\title{
PEMASYARAKATAN DAN PELATIHAN OLAHRAGA ADAPTIF PADA ANAK BERKEBUTUHAN KHUSUS
}

\section{(PROMOTING ADAPTIVE SPORTS AND TRAINING FOR SPECIAL NEEDS CHILDREN)}

\author{
Purwo Sri Rejeki ${ }^{1}$, Irfiansyah Irwadi ${ }^{2}$, Misbakhul Munir ${ }^{3}$, Hayuris Kinandita ${ }^{4}$, \\ Eka Arum Cahyaning Putri ${ }^{5}$, Soffil Yudha Mulyadi ${ }^{6}$, Septyaningrum Putri \\ Purwoto $^{7}$ \\ 1,2,3,4,5 Departemen Ilmu Faal dan Program Studi Magister Ilmu Kesehatan Olahraga, \\ Fakultas Kedokteran, ${ }^{6,7}$ Program Studi Magister Ilmu Kesehatan Olahraga, Fakultas \\ Kedokteran, Universitas Airlangga \\ e-mail: purwo-s-r@fk.unair.ac.id; purwo_faal@yahoo.com
}

\begin{abstract}
Inclusive children or children with special needs are those who have abnormalities in the process of growth or development; which can be physical, mental-intellectual, social, or emotional. The World Health Organization predicts that around 7\% of the world's total children population is inclusive children. Exercise that are adapted and modified according to their needs, the type of abnormality and the ability of inclusive children are able to improve motor and sensory abilities so that they will improve their quality of life. The purpose of this activity is to increase the knowledge and skills of parents with inclusive children in implementing adaptive exercise for their children. The method used was seminar and training. Activity evaluation was carried out using questionnaire to observe the increase of knowledge. This activity was attended by 31 parents and 31 inclusive children, with the highest parents' age range in 31-40 years, which is mothers $38.7 \%$; $41.9 \%$ father. The age of expecting mothers of inclusive children mostly ranges from 31-40 years (35.5\%). Increased knowledge about child development was $31 \%$ (pretest 68 , posttest 91.8) and increased knowledge about adaptive sports was $72.18 \%$ (pretest 49.6, posttest 85.4).
\end{abstract}

Keywords: adaptive sports, Inclusive children, increased knowledge, seminars, training

\section{abstrak}

Anak Berkebutuhan Khusus (ABK) adalah anak yang dalam proses pertumbuhan atau perkembangannya mengalami kelainan atau penyimpangan; yang bisa berupa fisik, mentalintelektual, sosial, atau emosionalnya. Organisasi kesehatan dunia memprediksi sekitar 7\% dari keseluruhan populasi anak dunia merupakan ABK. Olahraga yang diadaptasi dan dimodifikas sesuai dengan kebutuhan, jenis kelainan dan tingkat kemampuan ABK mampu memperbaiki kemampuan motoris dan sensoris sehingga akan meningkatkan kualitas hidupnya. Tujuan kegiatan ini adalah untuk meningkatkan pengetahuan dan ketrampilan orang tua ABK dalam melatih olahraga adaptif buat anak-anaknya. Metode yang digunakan adalah seminar dan pelatihan. Evaluasi keberhasilan kegiatan dilakukan dengan kuesioner untuk melihat peningkatan pengetahuan. Kegiatan dihadiri oleh 31 orang tua dan 31 ABK, dengan rentang usia orang tua terbanyak di 31-40 tahun yaitu ibu 38,7\%; ayah 41,9\%. Usia ibu mengandung ABK terbanyak di rentang 31-40 tahun (35,5\%). Peningkatan pengetahuan pada materi tumbuh kembang anak sebesar $31 \%$ (pretest 68 , posttest 91,8) dan peningkatan pengetahuan materi olahraga adaptif sebesar $72,18 \%$ (pretest 49,6 , posttest 85,4 ).

Kata kunci: ABK, pelatihan, peningkatan pengetahuan, olahraga adaptif, seminar 


\section{PENDAHULUAN}

Anak Berkebutuhan Khusus (ABK) adalah anak yang dalam proses pertumbuhan atau perkembangannya mengalami kelainan atau penyimpangan; yang bisa berupa fisik, mental-intelektual, sosial, atau emosionalnya (NCSE, 2014; Lee dkk, 2015). Hal ini secara nyata berbeda bila dibandingkan dengan anak lain seusianya sehingga mereka memerlukan pelayanan khusus. Organisasi kesehatan dunia memprediksi sekitar 7\% dari keseluruhan populasi anak dunia merupakan ABK. Jumlah ABK secara keseluruhan di Indonesia memang belum didapatkan data yang pasti, tetapi ABK yang menempuh pendidikan setingkat SD dan SMP di Indonesia mencapai sekitar 46.000 anak pada tahun 2014. Kondisi orang tua yang tidak tahu dari sisi pengetahuan dan tidak mampu secara finansial, akan membuat para orang tua tidak bisa merawat ABK dengan optimal dan memperparah kondisinya. Hal ini terjadi pada $3 \%$ populasi ABK (Kompasiana, 2012).

Pada ABK bisa memiliki masalah dalam fungsi sensoris, motoris, proses belajar, dan perilakunya. Masalah ini mengakibatkan terganggunya perkembangan fisik anak. Selain itu, sebagian besar ABK mengalami hambatan dalam merespon rangsangan yang diberikan lingkungan untuk melakukan gerak, meniru gerak dan bahkan ada yang memang fisiknya terganggu sehingga ia tidak dapat melakukan gerakan yang terarah dengan benar (NCSE, 2014).

Mitra pada kegiatan ini adalah Yayasan Peduli Anak Cerebral Palsy. Yayasan ini berlokasi di Jl. Jojoran 1 no 115A, Surabaya. Yayasan ini bertujuan untuk meningkatkan kualitas hidup dan kemuliaan anak berkebutuhan khusus melalui pendekatan terhadap ABK dan orang tuanya. Kegiatan yang selama ini dilakukan oleh yayasan adalah pendampingan ABK dan orang tuanya dalam peningkatan semua aspek ketrampilan dan pengetahuan yang berguna untuk meningkatkan kualitas hidup ABK. Beberapa kegiatan yang pernah dilakukan yaitu memberikan pelatihan bagaimana penyaringan informasi media untuk anak, pentingnya bermain untuk anak, pelatihan optimalisasi kemampuan mendengar dalam pengasuhan dan pembelajaran untuk orang tua, terapi pijat untuk anak dan masih banyak lagi kegiatan lainnya.

Permasalahan yang dihadapi bersifat kompleks, yaitu pendanaan, shelter, tenaga pendamping atau tenaga suka rela untuk mengkoordinasi kegiatan. Untuk peningkatan pengetahuan dan ketrampilan $\mathrm{ABK}$ dan orang tuanya juga dibutuhkan para konsultan dan tenaga ahli, yang dalam hal ini juga menjadi masalah buat yayasan ini. Bila menilik ABK yang dinaungi oleh yayasan ini, sebagaimana ABK lainnya juga mempunyai keterbatasan dalam fungsi motoris dan sensoris, sehingga dibutuhkan sebuah pengetahuan tentang bagaimana meningkatkan fungsi motoris dan sensorisnya.

Olahraga merupakan aktivitas yang dapat meminimalisasi Deconditioning Syndrome yaitu sekumpulan gejala yang memicu menurunnya kapasitas fungsional pada beberapa sistem tubuh akibat gerakan tubuh berkurang dalam jangka waktu yang lama (Lee dkk, 2010; Joyner dkk, 2012). Olahraga juga berperan untuk mengotipmalkan fungsi fisik, meningkatkan well-being serta kemampuan sosial. Namun, pada beberapa kondisi, ABK mempunyai kemampuan motorik yang menurun dan lebih rendah dibandingkan anak seusianya. Untuk itulah, dibutuhkan adaptasi gerakan yang kita sebut sebagai Olahraga Adaptif NCSE, 2014). 
Untuk itu diperlukan peningkatan pengetahuan dan ketrampilan olahraga adaptif pada pengelola yayasan, tenaga sukarela di yayasan ini, orang tua maupun pelatihan olahraga adaptif pada ABK yang diharapkan dapat meningkatkan fungsi motorik dan sensoriknya. Peningkatan pengetahuan dilakukan seminar dari pakar sedangkan peningkatan ketrampilan stimulasi fungsi motorik dan sensorik dengan pelatihan.

\section{METODE PENGABDIAN MASYARAKAT}

Untuk mencapai tujuan yang diharapkan, maka rancangan kegiatan pengabdian masyarakat ini dibagi menjadi dua kegiatan utama, yaitu seminar dan pelatihan. Tim pengabdian masyarakat bekerja sama dengan pengurus Yayasan untuk mengundang ABK beserta kedua orang tua atau pendampingnya. Orang tua atau pendamping yang diundang sejumlah dua orang bertujuan untuk satu orang sebagai peserta seminar, dan satu orang lagi mendampingi $\mathrm{ABK}$ untuk mendapatkan pelatihan. Dua kegiatan dilakukan secara paralel adalah untuk mempersingkat waktu pelaksanaan acara mengingat $\mathrm{ABK}$ akan kelelahan. Acara ini dihadiri oleh 31 orang $\mathrm{ABK}$ beserta pendampingnya.

Pada seminar materi yang diberikan adalah Tumbuh Kembang Anak Normal dan Tumbuh Kembang Anak dengan Palsi Serebral; yang diberikan oleh Mira Irmawati Sp. A (K), konsultan tumbuh kembang anak RSUD. Materi yang kedua adalah Peran Olahraga untuk Anak ABK oleh Ftr. Niniek Soetini, S.FT., M. Fis. Seminar ini melibatkan Dosen Departemen Ilmu Faal Fakultas Kedokteran (FK) UNAIR, Dosen Program Studi Magiseter Ilmu Kesehatan Olahraga (IKESOR) FK UNAIR dan mahasiswanya angkatan 2017 dan 2018 sebanyak 15 orang. Sebelum dilaksanakan seminar, orangtua mengisi kuesioner tentang riwayat tumbuh kembang anak. Kuesioner yang mengukur pengetahuan orang tua dan pendamping tentang tumbuh kembang anak beserta peran olahraga diberikan sebelum dan sesudah kegiatan seminar. Untuk penguatan materi, buku tentang fisiologi tumbuh kembang dan olahraga adaptif untuk ABK juga telah disusun.

Pada pelatihan olahraga adaptif pada ABK diberikan oleh trainer adalah senam cerebral palsy $(\mathrm{CP})$ yang mengajarkan gerakan-gerakan yang diadaptasikan sesuai kemampuan ABK palsi serebral. Sebelum pelatihan senam adaptif dilakukan pemeriksaan tanda vital, pengukuran antropometri dan range of movement anak. Senam CP yang diajarkan adalah senam CP yang dikreasi oleh Prodi Magister IKESOR FK UNAIR yang bisa diberikan kepada semua jenis $\mathrm{CP}$, dan merupakan passive movement, karena $\mathrm{ABK}$ digerakkan oleh pendamping. Senam CP merupakan senam berirama yang terdiri dari gerakan pemanasan selama 5 menit, gerakan inti 25 menit, dan pendinginan 5 menit (Verschuren dkk, 2007). Gerakan untuk CP ditekankan pada ekstremitas atas dan bawah (Ryan dkk, 2016), bahu, pergelangan dan jari-jari untuk merangsang otak (Insan dan Sutisna, 2016) dan diiringi lagu yang bersifat edukatif (Julidar, 2012). Video tentang gerakan senam CP ini juga sudah diberikan dalam bentuk compact disc yang dibagikan ke semua peserta.

\section{HASIL DAN PEMBAHASAN}

Seminar dan pelatihan diselenggarakan pada hari Sabtu, tanggal 29 September 2018, pukul $09.00 \mathrm{~s} / \mathrm{d} 12.00$. Seminar dan pelatihan berlangsung secara paralel di dua ruangan yang berbeda dan berjalan cukup efektif, walaupun sempat terkendala sedikit perihal 
teknis pengaturan pemeriksaan fisik $\mathrm{ABK}$ karena keadaan $\mathrm{ABK}$ yang memang memerlukan perhatian lebih agar tetap nyaman mengikuti serangkaian acara. Kendala ini dapat teratasi dengan baik berkat ketanggapan panitia dan instruktur serta kerjasama orang tua ABK dalam menciptakan kondisi yang kondusif untuk ABK.

\section{Karakteristik orang tua $\mathrm{ABK}$}

Karakteristik orang tua ABK berdasarkan usia ayah dan ibu sekarang dan usia ketika ibu mengandung bisa dilihat pada tabel 1 .

Tabel 1. Karakteristik orangtua ABK berdasarkan usia

\begin{tabular}{cccc}
\hline Usia (tahun) & Ibu* & Ayah* & Ibu** \\
\hline $21-30$ & $3(9,7 \%)$ & $1(3,2 \%)$ & $7(22,6 \%)$ \\
$31-40$ & $12(38,7 \%)$ & $13(41,9 \%)$ & $11(35,5 \%)$ \\
$41-50$ & $3(9,7 \%)$ & $4(12,9 \%)$ & $2(6,5 \%)$ \\
$>51$ & $1(3,2 \%)$ & $2(6,5 \%)$ & $0(0 \%)$ \\
Tidak mengisi & $12(38,7 \%)$ & $11(35,5 \%)$ & $12(38,7 \%)$ \\
Total & 31 & 31 & 31 \\
* usia pada saat pengisian kuesioner & & \\
$* *$ usia pada saat hamil & &
\end{tabular}

Tabel 1 menunjukkan bahwa usia 31-40 saat hamil menempati persentase tertinggi dari yang mengisi data tersebut. Sedangkan untuk usia saat hamil diatas 35 tahun sebanyak 7 orang dari 19 yang mengisi kuesioner. Usia ibu ketika mengandung mempunyai korelasi yang kuat dengan $\mathrm{CP}$, yaitu ibu yang mengandung di atas 35 tahun dan di bawah 20 tahun selain riwayat abortus sebelumnya, terapi fertilitas (Schneider dkk, 2018). Faktor risiko Cerebral palsy lainnya di antaranya adalah bayi lahir dengan berat badan rendah, infeksi intrauterin dan kehamilan yang multipel (Odding dkk, 2009).

Tingkat pendidikan orang tua ABK bisa dilihat di tabel 2 untuk melihat secara tidak langsung tingkat pengetahuan orang tua ABK.

Tabel 2. Karakteristik orangtua ABK berdasarkan tingkat pendidikan

\begin{tabular}{ccc}
\hline Tingkat pendidikan & ibu & ayah \\
\hline SD & $1(3,2 \%)$ & $2(6,5 \%)$ \\
SMP & $0(0 \%)$ & $1(3,2 \%)$ \\
SMA & $7(22,6 \%)$ & $5(16,1 \%)$ \\
PT & $10(32,3 \%)$ & $12(38,7 \%)$ \\
Tidak mengisi & $13(41,9 \%)$ & $11(35,5 \%)$ \\
Total & 31 & 31 \\
\hline
\end{tabular}

Dari tabel 2 bisa dilihat bahwa dari responden yang mengisi, maka prosentase terbesar pendidikan orang tua adalah di tingkat perguruan tinggi. Hal ini bisa disimpulkan bahwa tingkat pendidikan orang tua berkecenderungan tidak berkorelasi dengan kejadian cerebral palsy. Hal ini agak berbeda dengan metaanalisis yang mengatakan ada kecenderungan kuat antara risiko cerebral palsy dengan tingkat pendidikan orang tuanya (Forthun dkk, 2018). Ketidaksamaan ini bisa dikarenakan oleh ketidaksamaan persepsi tingkat pendidikan. Tingkat pendidikan orang tua yang berperan adalah tingkat pendidikan ketika memutuskan kehamilan dan bukan tingkat pendidikan sekarang. 


\section{Karakteristik Penyebab Kelainan Motorik}

Pada ABK pada kegiatan ini, keseluruhan mempunyai kelainan motorik yang berupa kelemahan dan spastisitas, selain rendahnya kognitif. Pada tabel 3 bisa dilihat penyebab kelainan motorik yang mendasarinya.

Tabel 3. Penyebab kelainan motorik ABK

\begin{tabular}{lcc}
\hline Klasifikasi penyebab & $\mathrm{n}$ & $\begin{array}{c}\text { Persentase } \\
(\%)\end{array}$ \\
\hline Cerebral Palsy & 22 & 71 \\
Trauma otak & 9 & 29 \\
Total & 31 & 100 \\
\hline
\end{tabular}

Kelainan motorik akan menentukan kualitas gerakan. Sedangkan Cerebral Palsy merupakan kata umum yang berlaku untuk sejumlah kondisi neurologis yang mempengaruhi gerakan dan koordinasi. Dari tabel 3, bisa dilihat bahwa persentase terbesar kelainan motorik di Yayasan ini ditegakkan sebagai cerebral palsy. Urutan persentase tersering kelainan berdasarkan pola motoriknya pada cerebral palsy adalah spastik, diskinetik dan ataksik. Gerakan yang dihasilkan mengikuti pola motorik diskinetik dan fungsi motorik yang jelek (Rice dkk., 2016). Dan kelainan ini yang didapatkan pada $\mathrm{ABK}$ di kegiatan pengabdian masyarakat ini.

\section{Luaran Kegiatan dan Perspektif Kegiatan}

Evaluasi penguasaan materi peserta diukur melalui pretest dan posttest. Peserta yang mengikuti pretest maupun postest sebanyak 22 orang. Sedangkan peserta yang mengikuti seminar sebanyak 45 orang. Perbedaan angka kehadiran peserta dan pengisi pretest posttest disebabkan karena beberapa hal, yaitu orangtua yang hadir lebih dari satu orang untuk masing- masing anak, adanya pemerhati ABK CP yang ikut dalam seminar, dan tidak lengkapnya identitas pada lembar pretest maupun posttest sehingga tidak dapat dinilai. Hasil pretest dan posttest bisa dilihat pada diagram 1.

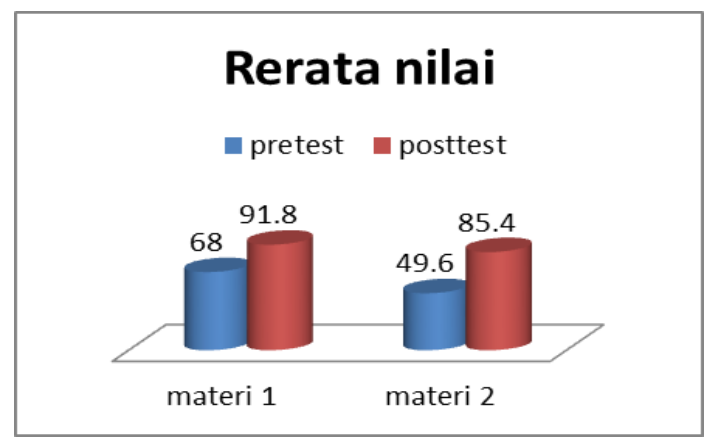

Diagram 1. Rerata nilai pretest dan posttest peserta

Pada diagram 1 dapat dilihat terdapat kenaikan nilai rerata dari pretest ke posttest sebesar 26\% untuk materi 1 yaitu Tumbuh Kembang Anak Normal dan Tumbuh Kembang Anak dengan Palsi Serebral dan kenaikan rerata dari nilai pretest ke posttest sebesar $42 \%$ untuk materi 2 yaitu Peran Olahraga untuk Anak ABK. Hal ini menunjukkan adanya peningkatan pengetahuan peserta tentang materi yang disampaikan. 
Beberapa usulan dari peserta seminar sebagai perspektif kegiatan selanjutnya adalah peningkatan pengetahuan tentang modalitas terapi pada $A B K$, nutrisi, dan pengayaan lingkungan yang berperan pada peningkatan kualitas hidup ABK.

\section{PENUTUP}

\section{Simpulan}

Pada orang tua ABK yang berpartisipasi aktif didapatkan usia terbanyak adalah 31-40 tahun dengan tingkat pendidikan terbanyak adalah perguruan tinggi. Peningkatan pengetahuan bisa dicapai dengan kegiatan seminar dan pelatihan.

\section{UCAPAN TERIMA KASIH}

Kegiatan ini didanai oleh Hibah Pengabdian Masyarakat Lembaga Pengabdian Masyarakat Universitas Airlangga dengan SK 562/UN3.15/PM/2018.

\section{DAFTAR PUSTAKA}

Children with Special Educational Needs, http://ncse.ie/wpcontent/ouploads/2014/10/ChildrenWithSpecialEdNeeds1.pdf

Forthun I, Stranberg-Larsen K, Wilcox AJ, Moster D, Petersen TG, Vik T, Lie RT, Uldall P, Tollanes MC. "Parental Socioeconomic Status and Risk of Cerebral Palsy in Child: Evidence from Two Nordic Population-Based Cohorts", International Journal of Epidemiology, Vol 47, issue 4, 1298-1306 https://doi,org/10.1093/ije/dyy139

Insan N, Sutisna N. 2016. "Pengaruh Metode Senam Otak Melalui Gerakan Arm Activation Terhadap Peningkatan Kemampuan Menulis Permulaan Anak Cerebral Plasy Spastic di SLB D YPAC Bandung”, JASSI_anakku volume 17 Nomor 1, Juni.

Joyner MJ. 2012. "Standing up for exercise: should deconditioning be medicalized?" The Journal of Physiology, 2012 Aug 1; 590(Pt 15): 3413-3414 doi: 10.1113/jphysiol.2012.238550

Julidar K. 2012. Penerapan Musik Sebagai Media Terapi Fisik Motorik Bagi Anak Penyandang Cerebral Palsy Di Yayasan Pembinaan Anak Cacat (YPAC) Semarang. Semarang: Universitas Negeri Semarang

Lee FLM, Yeung AS, Tracey D, Barker K. 2015. Inclusion of Children with Special Needs in Early Childhood Education: What Teacher Characteristic Matter, SAGE journals. https://doi.org/10.1177/0271121414566014

Lee SM, Moore AD, Everett ME, Stenger MB, Platts SH. 2010. Aerobic Exercise Deconditioning and Countermeasures During Bed Rest, Aviat Space Environ Med, Jan; 81 (1) 52-63 
Odding E, Roebroeck ME, and Stam HJ. 2006. "The Epidemiology of Cerebral Palsy: Incidence, Impairments and Risk Factors", Journal Disability and Rehabilitation Vol 28 issue 4, 2006, online 7 Jul 2009. https://doi.org/10.1080/09638280500158422

Perkembangan Pendidikan Anak Berkebutuhan Khusus di Indonesia, https://www.kompasiana.com/tanamilmu/55107ad1a33311273bba8243/perke mbangan-pendidikan-anak-berkebutuhan-khusus-di-indonesia?page=all

Rice J, Baker F, Russo R. 2016. "The Spectrum of Movement Disorders in A Cerebral Palsy Population”. Developmental Medicine \& Child Neurology Volume 58, Issue 55, 2016, https://doi.org/10.1111/dmcn.65_13224

Ryan JM, Theis N, Kilbride C, et al. 2016. Strength Training for Adolescents Cerebral Palsy (STAR): Study Protocol of a Randomized Controlled Trial to Determine the Feasibility, Acceptability and Efficacy of Resistance Training for Adolescents with Cerebral Palsy, BMJ Open, 6: e012839. http://dx.doi.org/ 10.1136/bmjopen-2016012839

Verschuren O, Ketelaar M, Gorter JW, Helders PJ, Uiterwaal CS, Takken T. 2007. "Exercise Training Program in Children and Adolescents with Cerebral Palsy: A Randomized Controlled Trial", Archives of Pediatrics and Adolescent Medicine, 161(11): 1075-1081. 